\title{
The role of suggested size in distance responses
}

\author{
WALTER C. GOGEL \\ University of California, Santa Barbara, California 93106
}

\begin{abstract}
A number of studies have concluded that suggested size can modify perceived size, as indicated by the effect on perceived distance. At least this effect seems to occur when verbal reports are used as the measure of the judged distance of the target. The present study supports a different explanation of this phenomenon. It is hypothesized that suggested size can result in the judgment that the target is larger or smaller than normal (an off-sized judgment) where normal is specified by the suggested size. Because the observer expects that a target judged as a small or large off-sized object must be at a greater or lesser distance, respectively. than its perceived distance, the off-sized judgment can provide a cognitive modification of reported distance. This explanation was tested by measuring the perceived distance of targets using a procedure (called the head motion procedure) that, in contrast with verbal reports of distance, is very unlikely to be influenced by off-sized judgments. Measures obtained with the head motion procedure, unlike those obtained from verbal reports, did not change with changes in the suggested size. It is concluded that the size suggestions had a cognitive, not a perceptual, effect on responses to the distance (and size) of the targets.
\end{abstract}

It has been concluded from a number of studies that providing an observer with information regarding the size of an otherwise ambiguous (blank) target, viewed under reduced conditions, will influence the perceived size of the target. Such additional (extraneous) information regarding target size not provided by information from the target itself can be supplied to the observer in several ways. One way is to give the target a familiar name (Baird, 1963; Hastorf, 1950; Park \& Michaelsen, 1974). Another way is to provide a tactile object said to be the same size as the target (Coltheart, 1969). A third way is to inform the observer verbally that the target is a particular size (Coltheart, 1970; Park \& Michaelsen, 1974). The effectiveness of these ways of attempting to modify the perceived size of the target can be measured by using the relation between perceived size and distance specified by the size-distance invariance hypothesis. According to this hypothesis, the larger the perceived size of the target (as possibly determined, in this case, by suggested size), the greater will be its perceived distance. The conclusion that extraneous sources of information modified perceived size in the above studies is supported by the observers' judgments that the distance of the target increased with increases in its suggested size. This conclusion, if valid, makes the important assertion that visual displays under reduced conditions of observation are easily modified in perceived size and perceived distance by information other than that obtained directly from the display. As discussed

This research was supported by Research Grant BNS 77-16620 from the National Science Foundation. The author wishes to thank Jerome D. Tietz for his assistance in constructing the apparatus and in gathering and analyzing the data. below, the present study questions this conclusion on the basis that the modification of the judged distance by suggested size in these studies is cognitive, not perceptual.

\section{THEORY}

\section{Cognitive Effects From Off-Sized Judgments}

There is evidence that observers expect that an object at a far distance will look smaller than the same object at a near distance (Carlson, 1960; Carlson \& Tassone, 1962). Conversely, an object that is judged to be smaller or larger than expected (a judgment of the object as off-sized) often will be assumed to be at a greater or lesser distance, respectively, than the distance at which it appears (Gogel, 1969; Gogel \& Newton, 1969). In the above studies, in which assumed (suggested) size was manipulated by extraneous information, when the suggested size was not identical to perceived size, the target would be judged to be off-sized. Specifically, a suggested size larger or smaller than the perceived size would be expected to result in the judgment that the target was a small or large off-sized object, respectively. Assuming that the observer used this off-sized information in the interest of giving accurate reports of distance, the target would be reported as being at a larger or smaller distance, respectively, than the distance at which it was perceived. If this occurred, the change in the reported distance as a function of the off-sized judgment would be cognitive, not perceptual. It would also follow in this case that the suggested size, while contributing to the judgment of the target as offsized, could not be said to have modified the perceived size of the target.' 
A cognitive modification of the response of distance as a result of information that the target is off-sized can be present only if the observer is aware that the task concerns a judgment of distance such as occurs, for example, in asking for a verbal report of distance. Only in that case could the response be modified by the off-sized information in an effort by the observer to be correct physically. On the other hand, if the observer is unaware that the perceived distance of the target is being measured or is unaware of the relation between the judgmental task and the perceived distance of the target, the offsized information is unlikely to have any effect on the distance measurement. One method of measuring perceived distance that meets this criterion of being unaffected by off-sized information is called the head motion procedure. This procedure uses the relation between the apparent motion of the stationary target concomitant with a lateral motion of the head and the perceived distance of the target (Gogel \& Newton, 1976). A comparison of the results obtained from the head motion procedure and from verbal reports of the target distance will be used in the present study to determine whether size suggestions can modify the perceived size of the target as reflected in their effect on its perceived distance or, instead, whether the modification is only on cognitive distance, with perceived size and perceived distance unchanged.

\section{The Head Motion Procedure}

The head motion procedure has been discussed elsewhere (Gogel, 1976, 1977; Gogel \& Tietz, 1979) and is described in detail in the caption of Figure 1. The procedure is based on the phenomenon that if a physically stationary object is misperceived in distance, it will appear to move concomitantly with the head as the head is moved laterally. The apparent concomitant motion will be in the direction of or opposite to that of the head motion, depending upon whether the perceived distance of the target is less or greater, respectively, than its physical distance. Furthermore, if the target is moved physically concomitantly with the head until this apparent motion disappears, the magnitude of the required physical motion can be used to calculate the perceived distance of the object (see the caption of Figure 1).

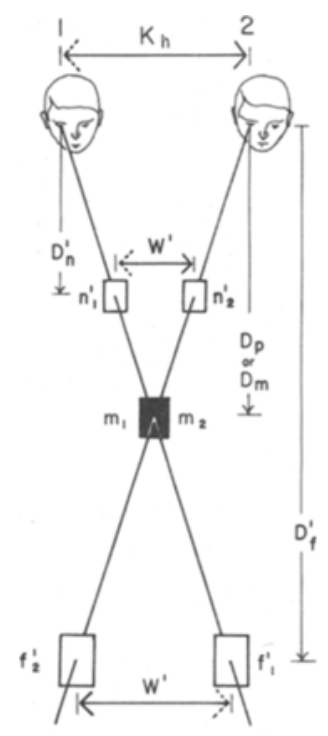

A

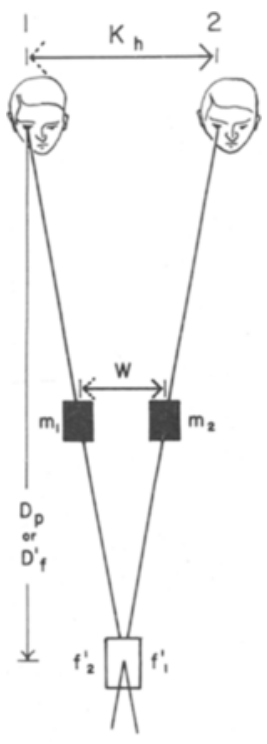

B

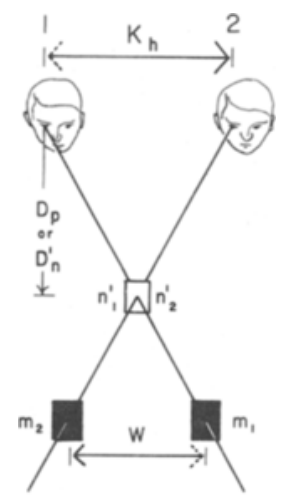

C

Figure 1. Principles involved in the head motion procedure. The prime notation and open rectangles indicated perceived extents and perceived positions, and the notation without primes and filled rectangles indicate physical extents and physical positions. The apparent concomitant motion $\left(W^{\prime}\right)$ of the stationary rectangle with or against the head motion $\left(K_{t}\right)$ as a function of the errors in perceived distance shown in $A$ is eliminated in $B$ and $C$ by physically moving the rectangle $a$ distance, $W$, as the head is moved, until the rectangle no longer appears to move. The apparent absolute distance of the rectangle $\left(D_{m}^{\prime}\right)$ is calculated from the physical motion (W) required to achieve this null perception using the equation $\left[D_{m}^{\prime}=K_{h} D /\left(K_{h}-W\right)\right]$, where $D$ is the physical distance of the rectangle from the observer. This calculation assumes that the observer correctly perceives the change in the direction of the rectangle per unit of lateral motion of the head (from Gogel \& Tietz, 1980). 
Since the observer is unaware of the dimension being measured with this procedure, the need or ability to invoke a cognitive correction (using the information that the target is off-sized) in an effort to give a correct report of distance is not present.

There are two kinds of cognitive effects that have been identified as distorting the verbal report as a measure of perceived distance. One of these, as indicated above, results from judging the target as off-sized. The other is a tendency for the observer to underestimate or to misapply the size of a foot ruler when giving verbal reports of distance. This latter effect was corrected (calibrated) in the present study by obtaining verbal reports of distance in a situation in which many cues of distance were available. The logic and validity of this calibration procedure are discussed elsewhere (Gogel \& Tietz, 1974; Mershon, Kennedy, \& Falacara, 1977).

\section{EXPERIMENT}

\section{Method}

\section{Observers}

The observers were 64 students ( 42 women and 22 men) with an average age of 19 years, who, by their participation in the experiment, partially fulfilled a requirement of an introductory course in psychology. All had a visual acuity of $20 / 20$ in each eye and were naive regarding the purpose of the experiment.

\section{Apparatus}

The apparatus used in the experimental situations is illustrated schematically in Figure 2. It consisted of targets (blank geometric figures or points of light) to be judged as to distance and a method of physically moving the target laterally by adjustable amounts concomitant with the lateral motion of the observer's head. Familiar objects were used to provide the extraneous information (suggestion) regarding the size of the blank targets. The familiar objects were either rectangular or circular in shape

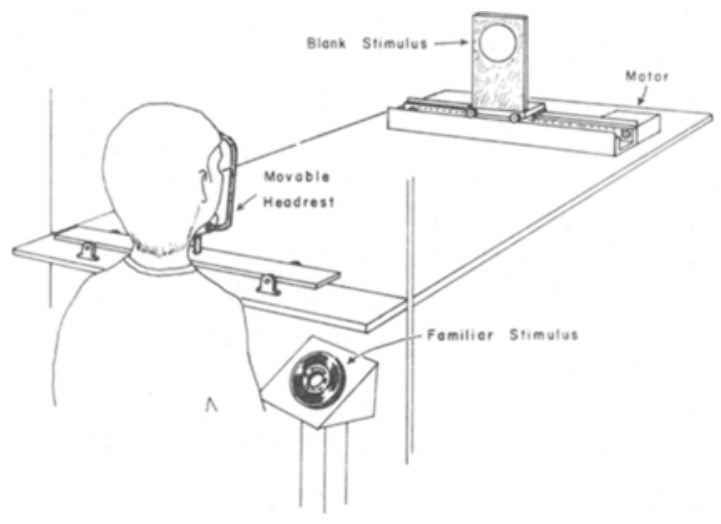

Figure 2. Apparatus for laterally moving the point of light in the practice trials or the blank target stimulus in the experimental trials concomitant with the lateral motion of the head in the head-and chinrest. The familiar stimulus used in the experimental trials to produce the assumed or suggested size is shown to the right of the observation position. and were mounted rigidly on a Masonite board in a manner such that their shape could readily be viewed and felt by the observer. The Masonite board was located in the observation booth to the right of the observer's position and could be seen by the observer when a light in the observation booth was turned on. The familiar rectangular objects were a copy of a Readers Digest $(13.7 \mathrm{~cm}$ wide $\times 18.8 \mathrm{~cm}$ high) and a similarly shaped, but smaller, 8 of spades playing card $(6.3 \times 8.8 \mathrm{~cm})$. The familiar circular objects were a $45-\mathrm{rpm}$ record $(17.3 \mathrm{~cm}$ in diameter) and a smaller silver dollar $(3.8 \mathrm{~cm}$ in diameter).

The blank targets, to be judged in distance, were a luminous rectangle or disk with linear dimensions $(10.0 \times 13.8 \mathrm{~cm}$ or $10.5 \mathrm{~cm}$ in diameter) that were the average of those of the two familiar objects of the same shape. They were formed by appropriately masking a white electroluminescent panel having a luminance of $.06 \mathrm{~cd} / \mathrm{m}^{2}$. The blank targets were presented monocularly one at a time and were mounted on a cart that was movable laterally in a frontoparallel plane at a distance of $120 \mathrm{~cm}$ from the observer when the observer's head was at the midpoint of its lateral motion. A point of light target, instead of a blank target, also could be presented on the movable cart and was used to provide preliminary experience for the observers with the head motion procedure. The point of light was $1.0 \mathrm{~mm}$ in diameter and was presented binocularly on the movable cart at either 80 or $160 \mathrm{~cm}$ from the observer's eyes. An occluder on the headand chinrest that covered the left eye of the observer whenever a blank stimulus was presented was raised to provide binocular observation of the point. When either a blank stimulus or a point of light was presented, nothing was visible to the observer except this single target.

The observer's head was in a head- and chinrest that moved on ball bearings between cushioned stops through a right-left distance of $12.5 \mathrm{~cm}$. The motion was paced to arrive at each stop in time with a metronome click presented over a loudspeaker every $1.5 \mathrm{sec}$. The point of light or blank target stimulus was viewed through a large aperture that could be occluded, and the target was mounted in a holder on a cart (see Figure 2), with the cart movable laterally on a track. A chain and sprocket drive was attached to the cart, with the drive controlled by a motor that the experimenter could vary in speed and direction. The motor was part of an electronic servo system that physically moved the point of light or blank target laterally concomitant with the physical lateral motion of the head. The position and motion of the head-and chinrest were communicated to the servo system by another gear and chain connection. The output from the servo system was controlled by the experimenter's using a knob located outside the observation booth. By adjusting the knob, the physical motion of the point or blank target stimulus concomitant with the motion of the head could be varied in any amount from a motion in the same direction as that of the head to a motion opposite to the head motion. The apparent distance of the target stimulus was computed from the physical motion adjusted to achieve a criterion of no apparent motion of the target.

The track containing the movable cart could be positioned in distance to present the target at the required distance. A large white cardboard, having a luminance of $27 \mathrm{~cd} / \mathrm{m}^{2}$ when the booth light was turned on, was located on the left wall of the observation booth and provided a light adaptation surface to be viewed between trials, Communication between the experimenter and observer was by means of microphones and loudspeakers.

To calibrate the verbal reports of distance, six white $(10 \mathrm{~cm})$ squares, randomly numbered, were placed upright on the floor of a visual alley. The calibration alley was in a room different from the room used for the experimental situations. The calibration alley, which was illuminated from overhead throughout its length, was $95 \mathrm{~cm}$ wide $\times 800 \mathrm{~cm}$ long, with tan cloth covering the floor, and black cloth used to form the walls. The squares were presented simultaneously along the alley floor at distances from the observer of $40,100,200,350,500$, and $650 \mathrm{~cm}$ and were positioned so that no square occluded any part of another when 
viewed from the observation position. The floor of the alley was $30 \mathrm{~cm}$ below the eye level of the observer, and the viewing was binocular through a large aperture that could be closed by a shutter. The observer's task was to report verbally the apparent distance of each of the six squares from the eyes.

\section{Procedure}

The observer was given preliminary instructions as to what was meant by apparent motion of the target in the same direction as the head ("with" motion) and opposite to the head motion ("against" motion) and the adjustment to the apparent no-motion (null) criterion. It was explained that a bracketing technique would be used to achieve the null criterion. With this technique, the null criterion was approached alternately from apparent motion with and against the head, using successively smaller increments of cart motion. The observer was instructed to fixate the target throughout this procedure. Following the preliminary instruction, with the observation shutter closed, the observer practiced moving the head smoothly right and left in the headand chinrest in time with the metronome.

The practice trials. A practice trial using the head motion procedure consisted of the following. The light in the observation booth was turned off, the head was moved right and left repeatedly in the head- and chinrest, the viewing aperture was opened, and the observer saw a single point of light in an otherwise dark visual field (at the near or far distance). While moving the head, the observer reported whether the point appeared to move "with" or "against" the head motion. The experimenter turned the adjustment knob (which had initially been set randomly to an extreme position to produce "with" or "against" motion) to decrease the magnitude of the apparent concomitant motion of the point and, guided by the observer's responses, reached the criterion of no apparent motion using the bracketing technique. While continuing to move the head, the observer indicated verbally in feet or inches, or in some combination of both, how far the point of light was from the eyes. Following this, the viewing shutter was closed, and the observer turned to look at the light adaptation surface until the next practice trial, at which time the point of light was presented at the other distance. The order in which the near and far distances of the point of light were presented was varied systematically between observers.

The experimental trials. Following the two practice trials with the points of light, a blank target was mounted on the movable cart, and the experimenter placed one of the four familiar objects in the lighted observation booth, as indicated in Figure 2. The observer examined the familiar object both visually and tactually and was informed that the object (the blank target) to be seen through the viewing aperture had the same size and shape as the familiar object. The booth light was then turned off, and while the observer moved his head in the head- and chinrest, the viewing shutter was raised, revealing the blank target stimulus and beginning an experimental trial. The observer continued to feel the familiar object with the right hand while moving his head left and right in the head- and chinrest. After being reminded that the object (target) being viewed had the same size and shape as the familiar object, the target was adjusted to the null criterion using the bracketing technique, and while continuing to move the head, the observer indicated in feet, inches, or some combination of both, the distance of the target from the eyes. The extraneous information regarding size was communicated to an observer by two familiar objects, one presented in each of the two successive trials. The familiar object used to provide the suggested size and the blank target presented on a particular trial were always of the same shape.

Four groups of 16 observers were used. Group 1 received the Readers Digest as the familiar object on the first trial and the silver dollar on the second, Group 2 received the playing card on the first trial and the 45-rpm record on the second, Group 3 received the silver dollar on the first trial and the Readers Digest on the second, and Group 4 received the $45-\mathrm{rpm}$ record on the first trial and the playing card on the second. Thus, a large or small familiar object and a blank target of one shape on the first trial were followed on the second trial by a small or large familiar object, respectively, and a blank target of the other shape. The verbal report of the distance of the blank target, with the observer continuing to move his head, always followed the adjustment of the target to the null criterion.

The calibration trials. The calibration situation, using the visual alley with many distance cues and binocular observation, was always presented following the experimental trials. The order in which the apparent distances of the squares at the six physical distances was reported was determined randomly, with a different random order used with each observer.

\section{Results}

The results from the head motion method of measuring perceived distance are labeled $D_{m}^{\prime}$. The results from the verbal reports of distance as given by the observer are labeled $D_{v}$, and the correction of these reports by the calibration procedure, using the results from the calibration alley, are labeled $D_{\mathrm{v}}^{\prime}$. The $D_{m}^{\prime}$ scores were calculated for each observer from the physical concomitant motion of the target (W of Figure 1) required in order for the target to appear stationary as the head was moved. The $D_{v}^{\prime}$ scores from the experimental situations were found from the $D_{v}$ scores by using the data obtained from the calibration alley as follows. A power function was computed for each observer from the reported $\left(D_{\mathrm{v}}\right)$ and physical (D) distances of the numbered squares in the calibration alley by converting these values to logarithms and obtaining a linear line of best fit using the method of least squares. From the average coefficient and exponent of the resulting individual power functions, the equation relating $D_{v}$ and $D$ in the calibration alley was $D_{v}=.5 D^{1.1}$. This equation is similar to that obtained by Gogel and Tietz (1974). Assuming that physical distance $D$ in the calibration alley was perceived correctly, the average equation for converting $D_{v}$ obtained in the experimental trials to $D_{v}^{\prime}$ was $D_{v}^{\prime}=2 D_{v}^{91}$. Rather than using this average calibration equation, however, individual calibration equations, as calculated from the distance reports of each observer in the calibration alley were applied to the $D_{v}$ data. Since the distributions of data sometimes were skewed, the results from both the practice and experimental trials were converted to logarithms for purposes of analysis.

The results from presenting the point of light at the near $(80 \mathrm{~cm})$ and far $(160 \mathrm{~cm})$ distance on the practice trials are summarized in Table 1 . The $D_{m}^{\prime}$, $D_{v}$, and $D_{v}^{\prime}$ geometric means for the far point are significantly larger than the corresponding geometric means for the near point beyond the .01 level $\left[t(63)=17.38\right.$ for $D_{m}^{\prime}, t(63)=12.95$ for $D_{v}$, and $t(63)=$ 12.55 for $\left.D_{v}^{\prime}\right]$. It is of interest to note that the calibration of $D_{v}$ resulted in average perceived distance scores $\left(D_{v}^{\prime}\right)$ of the point of light that were very similar to those obtained from the head motion pro- 
Table 1

Results From the Points of Light at 80 and $160 \mathrm{~cm}$ as Obtained From the Head Motion Procedure $\left(D_{m}^{\prime}\right)$, the Verbal Reports of Distance $\left(D_{\mathbf{v}}\right)$, and the Calibrated Verbal Reports of Distance $\left(D_{\mathrm{v}}^{\prime}\right)$

\begin{tabular}{lrrrrrrr}
\hline & \multicolumn{3}{c}{ Near $(80 \mathrm{~cm})$} & & \multicolumn{3}{c}{ Far $(160 \mathrm{~cm})$} \\
\cline { 2 - 4 } \cline { 6 - 7 } & $\mathrm{D}_{\mathbf{m}}^{\prime}$ & $\mathrm{D}_{\mathbf{v}}$ & $\mathrm{D}_{\mathbf{v}}^{\prime}$ & & $\mathrm{D}_{\mathbf{m}}^{\prime}$ & \multicolumn{1}{c}{$\mathrm{D}_{\mathbf{v}}$} & $\mathrm{D}_{\mathbf{v}}^{\prime}$ \\
\hline Mean & 109 & 70 & 114 & & 212 & 162 & 219 \\
Geometric Mean & 105 & 57 & 100 & & 203 & 108 & 181 \\
Median & 104 & 61 & 99 & & 202 & 91 & 169 \\
SD & 34 & 77 & 67 & 68 & 368 & 199 \\
\hline
\end{tabular}

cedure $\left(D_{m}^{\prime}\right)$. Since cognitive sources of information were absent in the trials using the point of light, the similarity of these measures was expected.

Table 2 shows the results from the experimental trials in which the blank targets were used and were at the constant $(120 \mathrm{~cm})$ distance. The comparisons of particular interest are those between the presentations in which familiar objects of the same shape as the blank target but of different familiar size were used to vary the magnitude of the extraneous size information. For the blank rectangular target, these are the comparisons between the trials using the Readers Digest (large familiar size) and the playing card (small familiar size). For the blank disk target, the comparisons of interest are between the trials using the 45-rpm record (large familiar size) and silver dollar (small familiar size). Table 2 shows the results obtained from the first and second trials (presentations), in which different familiar objects were used with a particular group of observers, and also the combination of these results, disregarding the order in which the trials were presented. Consider, first, the combined results shown in the lower third of Table 2. The $D_{v}^{\prime}$ geometric mean for the rectangular blank stimulus was $125 \mathrm{~cm}$ when the Readers Digest was used and $86 \mathrm{~cm}$ when the playing card was used. This difference of $39 \mathrm{~cm}$ was significant at the .05 level with a one-tailed test $[t(62)=2.11]$. The $D_{v}^{\prime}$ geometric mean for the circular blank stimulus was $142 \mathrm{~cm}$ when the $45-\mathrm{rpm}$ record was used and $68 \mathrm{~cm}$ when the silver dollar was used. This difference of $74 \mathrm{~cm}$ was significant at the .01 level $[t(62)=3.84]$. The geometric means of $D_{v}$ agree with these results, with the two differences of $76-44 \mathrm{~cm}$ and $77-40 \mathrm{~cm}$ both significant at the .01 level $[\mathrm{t}(62)=3.05$ and 2.92 , respectively]. According to the verbal reports of the distance of the blank target (physically always at a constant distance of $120 \mathrm{~cm}$ ), the larger suggested size produced a larger verbal report of distance, a result seemingly in agreement with the conclusion that the extraneous information had indeed modified perceived size and perceived distance.

The pattern of results obtained from $D_{m}^{\prime}$ with the blank targets differs markedly from the pattern found from $D_{v}$ and $D_{v}^{\prime}$. Consistent with a conclusion that the blank stimuli remained at the same perceived distance despite the different suggested sizes, no signif-

Table 2

Results From the Blank Targets at $120 \mathrm{~cm}$ as Obtained From the Head Motion Procedure $\left(D_{m}^{\prime}\right)$, the Verbal Reports of Distance $\left(D_{v}\right)$, and the Calibrated Verbal Reports of Distance $\left(D_{v}^{\prime}\right)$

\begin{tabular}{|c|c|c|c|c|c|c|c|c|c|c|c|c|}
\hline & \multicolumn{6}{|c|}{ Rectangular Familiar Object } & \multicolumn{6}{|c|}{ Circular Familiar Object } \\
\hline & \multicolumn{3}{|c|}{ Large (Readers Digest) } & \multicolumn{3}{|c|}{ Small (Playing Card) } & \multicolumn{3}{|c|}{ Large (45-rpm Record) } & \multicolumn{3}{|c|}{ Small (Silver Dollar) } \\
\hline & $\mathrm{D}_{\mathrm{m}}^{\prime}$ & $\mathrm{D}_{\mathbf{v}}$ & $\mathrm{D}_{\mathbf{v}}^{\prime}$ & $\mathrm{D}_{\mathrm{m}}^{\prime}$ & $\mathrm{D}_{\boldsymbol{v}}$ & $\mathrm{D}_{\mathbf{v}}^{\prime}$ & $\mathrm{D}_{\mathbf{m}}^{\prime}$ & $\mathrm{D}_{\mathbf{v}}$ & $\mathrm{D}_{\mathbf{v}}^{\prime}$ & $\mathrm{D}_{\mathbf{m}}^{\prime}$ & $\mathrm{D}_{\mathrm{v}}$ & $\mathrm{D}_{\mathrm{v}}^{\prime}$ \\
\hline & \multicolumn{12}{|c|}{ First Presentations } \\
\hline & \multicolumn{3}{|c|}{ Group 1} & \multicolumn{3}{|c|}{ Group 2} & \multicolumn{3}{|c|}{ Group 4} & \multicolumn{3}{|c|}{ Group 3} \\
\hline $\begin{array}{l}\text { Mean } \\
\text { Geometric Mean } \\
\text { Median } \\
\text { SD }\end{array}$ & $\begin{array}{r}187 \\
177 \\
172 \\
68\end{array}$ & $\begin{array}{r}214 \\
96 \\
122 \\
479\end{array}$ & $\begin{array}{l}135 \\
106 \\
124 \\
104\end{array}$ & $\begin{array}{l}212 \\
189 \\
170 \\
124\end{array}$ & $\begin{array}{l}56 \\
48 \\
61 \\
28\end{array}$ & $\begin{array}{r}118 \\
97 \\
108 \\
83\end{array}$ & $\begin{array}{l}186 \\
156 \\
137 \\
144\end{array}$ & $\begin{array}{r}121 \\
86 \\
114 \\
87\end{array}$ & $\begin{array}{l}175 \\
125 \\
158 \\
127\end{array}$ & $\begin{array}{l}240 \\
195 \\
156 \\
222\end{array}$ & $\begin{array}{l}67 \\
50 \\
46 \\
70\end{array}$ & $\begin{array}{l}90 \\
80 \\
74 \\
57\end{array}$ \\
\hline \multirow{2}{*}{$\mathrm{SD}$} & \multicolumn{12}{|c|}{ Second Presentations } \\
\hline & \multicolumn{3}{|c|}{ Group 3} & \multicolumn{3}{|c|}{ Group 4} & \multicolumn{3}{|c|}{ Group 2} & \multicolumn{3}{|c|}{ Group 1} \\
\hline $\begin{array}{l}\text { Mean } \\
\text { Geometric Mean } \\
\text { Median } \\
\text { SD }\end{array}$ & $\begin{array}{r}208 \\
195 \\
174 \\
84\end{array}$ & $\begin{array}{l}81 \\
60 \\
69 \\
70\end{array}$ & $\begin{array}{l}201 \\
148 \\
156 \\
239\end{array}$ & $\begin{array}{r}182 \\
175 \\
178 \\
56\end{array}$ & $\begin{array}{l}60 \\
41 \\
30 \\
58\end{array}$ & $\begin{array}{l}98 \\
76 \\
63 \\
81\end{array}$ & $\begin{array}{r}169 \\
156 \\
150 \\
70\end{array}$ & $\begin{array}{r}110 \\
69 \\
91 \\
94\end{array}$ & $\begin{array}{l}215 \\
162 \\
222 \\
135\end{array}$ & $\begin{array}{r}154 \\
142 \\
137 \\
66\end{array}$ & $\begin{array}{l}42 \\
31 \\
30 \\
37\end{array}$ & $\begin{array}{l}70 \\
57 \\
51 \\
51\end{array}$ \\
\hline \multirow{2}{*}{$\mathrm{SD}$} & \multicolumn{12}{|c|}{ Data Combined From Both Presentations } \\
\hline & \multicolumn{3}{|c|}{ Groups 1 and 3} & \multicolumn{3}{|c|}{ Groups 2 and 4} & \multicolumn{3}{|c|}{ Groups 2 and 4} & \multicolumn{3}{|c|}{ Groups 1 and 3} \\
\hline $\begin{array}{l}\text { Mean } \\
\text { Geometric Mean } \\
\text { Median } \\
\text { SD }\end{array}$ & $\begin{array}{r}198 \\
186 \\
172 \\
76\end{array}$ & $\begin{array}{r}147 \\
76 \\
84 \\
343\end{array}$ & $\begin{array}{l}168 \\
125 \\
132 \\
184\end{array}$ & $\begin{array}{r}197 \\
182 \\
170 \\
96\end{array}$ & $\begin{array}{l}58 \\
44 \\
38 \\
45\end{array}$ & $\begin{array}{r}108 \\
86 \\
78 \\
81\end{array}$ & $\begin{array}{l}178 \\
156 \\
143 \\
112\end{array}$ & $\begin{array}{r}115 \\
77 \\
99 \\
89\end{array}$ & $\begin{array}{l}195 \\
142 \\
176 \\
131\end{array}$ & $\begin{array}{l}197 \\
166 \\
144 \\
167\end{array}$ & $\begin{array}{l}54 \\
40 \\
38 \\
56\end{array}$ & $\begin{array}{l}80 \\
68 \\
66 \\
54\end{array}$ \\
\hline
\end{tabular}


icant changes in $D_{m}^{\prime}$ were obtained as a function of the size suggested by the familiar object. According to the $\mathrm{D}_{\mathrm{m}}^{\prime}$ geometric means, the rectangular blank stimulus was perceived to be at $186 \mathrm{~cm}$ when the Readers Digest was used and at $182 \mathrm{~cm}$ when the playing card was used, while the $\mathrm{D}_{\mathrm{m}}^{\prime}$ geometric means for the circular blank stimulus are $156 \mathrm{~cm}$ when the 45-rpm record was used and $166 \mathrm{~cm}$ when the silver dollar was used. Neither of these differences (the latter is opposite in direction to that obtained with $\mathrm{D}_{\mathrm{v}}^{\prime}$ ) is significant at the .05 level [ $\mathrm{t}(62)=$ .23 and .52 , respectively]. According to the $D_{m}^{\prime}$ results from the combined presentations, the change in the suggested sizes of the blank stimuli provided by the familiar objects produced no change in perceived distance and thus no change in perceived size.

The conclusions from the combined data are supported by the direction of the changes in the geometric means when the results are separated into first and second presentations. According to an analysis of variance, the $D_{m}^{\prime}$ and $D_{v}^{\prime}$ geometric means differed significantly at the .05 level as a function of suggested size in the second presentations $[\mathrm{F}(1,120)=13.01, \mathrm{p}<.01]$ but not in the first presentations $[F(1,120)=3.48$, $\mathrm{p}>$.05]. A similar analysis comparing the $\mathrm{D}_{\mathrm{m}}^{\prime}$ and $\mathrm{D}_{\mathrm{v}}$ data was significant for both the first and second presentations $[F(1,120)=8.75, p<.01$, and $F(1,120)=$ $4.68, p<.05$, respectively]. A separate analysis of the geometric means of $D_{m}^{\prime}$ provided no evidence that this measure differed significantly as a function of suggestion in either the first or second presentations at the .05 level $[F(1,60)=1.39$ and 1.19 , respectively]. On the other hand, the results from $D_{v}$ and $D_{v}^{\prime}$ are consistent with the conclusion that the verbal reports did differ as a function of suggestion in the predicted directions. Suggestion resulted in significant changes in the geometric means of $D_{v}$ for both the first and second presentations at the .01 level $[F(1,60)=8.58$ and 20.95 , respectively $]$ and in significant changes in the geometric means of $D_{v}^{\prime}$ in the second presentations $[F(1,60)=6.78, p<.05]$ but not in the first presentations $[F(1,60)=2.12$, $p>.05]$. The experiment supports the conclusion that although suggested size was able to modify the verbal reports of distance in the expected directions, it was unable to modify perceived distance as measured by the head motion procedure.

\section{DISCUSSION}

There is considerable evidence that the convergence of the eyes can be an effective cue of perceived distance for distances within several meters from the observer (see Foley, 1980). The binocularly observed point of light at $80 \mathrm{~cm}$ should have and did appear closer than the point at $160 \mathrm{~cm}$. This expected result was obtained with both the head motion and verbal procedures. Two conclusions are consistent with these data. First, the head motion procedure provided a measure of apparent distance that varied in the direction expected from the change in convergence, even with unpracticed observers. Second, in the case in which cognitive effects were absent or minimal, the calibrated verbal report and head motion procedure provided similar measures of perceived distance. The perceived distance of the point of light, although varying with physical distance, was not veridical. Table 1 shows that there was a tendency to overestimate the distance of both points. This is consistent with the concept of the specific distance tendency that has been shown to result in an overestimation of the distance of objects less than about $3 \mathrm{~m}$ from the observers when only oculomotor cues of distance are available (Gogel \& Tietz, 1974).

The data of Table 2 indicate that the extraneous information regarding size introduced by the experimenter had a clear effect upon the verbal reports of the blank targets in the expected direction. However, the data from the head motion procedure also clearly show that the perceived distance and thus the perceived size of the blank target remained unmodified by the suggestions regarding size. It is concluded that the effects of the size suggestions were cognitive, not perceptual.

The blank targets, unlike the points of light, were viewed monocularly in this study. The reason for this is that it seemed likely that cognitive information regarding distance from off-sized perceptions would contribute less to the verbal report of distance (relative to the contribution of perceived distance) as the precision of the cues specifying perceived distance increased (Gogel \& Sturm, 1971). If the viewing had been binocular, the information from perceived distance would have been more precise and the ability of suggested size to modify the verbal reports of distance would have been reduced. For example, if the blank target had been seen as resting on an alley floor under full distance cues, it is unlikely that suggested size would have had any influence upon the verbal reports of its distance.

In a previous study (Gogel, 1976), the head motion and verbal report procedures were applied to the measurement of perceived distance from familiar size. Although the effect of familiar size was found to be much more pronounced with verbal reports than with the head motion measure of perceived distance, both procedures indicated a change in perceived distance as a function of familiar size. In that study, unlike the present study, the familiar configuration was part of the target stimulus. Possibly, in the present study, the observers were unwilling to believe that the size suggested by the extraneous stimulus was the size of the target. It should 
be noted, however, that the suggested size was sufficient to modify clearly the verbal reports of distance. Considering both studies, it seems that the introduction of suggested size by using a target with a familiar configuration, rather than using a familiar comparison stimulus asserted to be the same size as the target, can change somewhat the perception of target size. Together the two studies begin to define the conditions under which learned or suggested information regarding size can contribute to the perception of size and distance.

In the present study, the off-sized judgments did not necessarily tend to lead to verbal reports of distance that were accurate. Under circumstances in which the suggested and physical sizes of the target are the same, however, such judgments would be expected to reduce errors in verbal reports of distance. For example, suppose that, for some reason, a house at a far distance appears at a near distance, perhaps because of the decrease in the effectiveness of many distance cues with increasing physical distance. In this case, consistent with the size-distance invariance hypothesis, the house would be perceived to be smaller in size than would be indicated by its familiar size. The resulting cognitive judgment that the small off-sized house was at a greater distance than its perceived distance would reduce or eliminate the error in the distance response that would occur from a reliance on perceived distance alone. ${ }^{2}$ Although, as discussed above, familiar size can modify perceived distance somewhat, its major contribution may be to cognitive distance. Thus, familiar size or any other valid indicator of physical size can provide an important factor in the correction of errors that might otherwise occur with distance responses based exclusively on perceived distance.

\section{REFERENCES}

BAIRD, J. C. Retinal and assumed size cues as determinants of size and distance perception. Journal of Experimental Psychology, 1963, 66, 155-162.

Carlson, V. R. Overestimation in size constancy judgments. American Journal of Psychology, 1960, 73, 199-213.

Carlson, V. R., \& Tassone, E. P. A verbal measure of perspective attitude. American Journal of Psychology, 1962, 75, 644-647.

Coltheart, $M$. The influence of haptic size information upon visual judgments of absolute distance. Perception \& Psychophysics, 1969, 5, 143-144.

Colthenat, $M$. The effect of verbal size information upon visual judgments of absolute distance. Perception \& Psychophysics, $1970,9,222-223$.
Foley, J. M. Binocular distance perception. Psychological Review, $1980,87,411-434$.

Gooes, W. C. The effect of object familiarity on the perception of size and distance. Quarterly Journal of Experimental Psychology, $1969,21,239-247$.

Goost, W. C. An indirect method of measuring perceived distance from familiar size. Perception \& Psychophysics, 1976, 20, 419-429.

Goosl, W. C. An indirect measure of perceived distance from oculomotor cues. Perception \& Psychophysics, 1977, 21, 3-11.

Goger, W. C., \& Newton, R. E. Perception of off-sized objects. Perception \& Psychophysics, 1969, 5, 7.9.

Gogel, W. C., \& Newton, R. E. An apparatus for indirect measurement of perceived distance. Perceptual and Motor Skills, 1976, 43, 295-302.

Gogel, W. C., \& STURm, R. D. Directional separation and the size cue to distance. Psychologische Forschung, 1971, 35, 57-80.

Gogel, W. C., \& Tietz, J. D. The effect of perceived distance on perceived movement. Perception \& Psychophysics, 1974, 16, $70-78$.

Gogel, W. C., \& TIETz, J. D. A comparison of oculomotor and motion parallax cues of egocentric distance. Vision Research, $1979,19,1161-1170$.

Gogel, W. C., \& TiETz, J. D. Relative cues and absolute distance perception. Perception \& Psychophysics, 1980, 28, 321-328.

HAstorF, A. H. The influence of suggestion on the relationship between stimulus size and perceived distance. Journal of Psychology, 1950, 29, 195-217.

Mershon, D. H., Kennedy, M., \& Falacara, G. On the use of calibration equations in perception research. Perception, 1977, 6, 299-311.

Park, J. N., \& Michaelsen, G. J. Distance judgments under different size-information conditions. Perception \& Psychophysics, 1974, 15, 57-60.

\section{NOTES}

1. The experience of an object as off-sized might be called an "off-sized perception" rather than an "off-sized judgment," since the object is seen to be larger or smaller than expected. What is meant by either expression is that the apparent (perceived) size of the object differs from its expected (normal) size. Thus, the same perceived size could result in either a large or small offsized judgment, depending upon the expected or assumed size. Indeed, if the perceived size were determined by expected size, the object would always be judged to be normal in size. In other words, the experience of an object as off-sized can occur only if the suggested, expected, or assumed size does not determine perceived size. Thus, it is probably better to use the expression "off-sized judgment" (as in the present paper) rather than "offsized perception"' (as used, e.g., by Gogel, 1969; Gogel \& Newton, 1969).

2. A quantitative description of the relation between off-sized judgments and cognitive distance and of the weighing of perceptual and cognitive factors in the judgment of distance is given in the study by Gogel (1976).

(Received for publication January 26, 1981; revision accepted May 6,1981 .) 